\title{
Environmental Issues Concerning the Economic Development of Tourism in Iraq \\ Al-Saadi $\mathbf{N}$ \\ Department of Geography, University of Bucharest, Romania
}

\begin{abstract}
Environmental pollution is one of the main factors that stand as an obstacle in the development of the tourism sector. In Iraq within the last three decades, this issue has had significant impacts on the ecological, economic and social sectors, particularly on the tourism sector. Within the context of a structural adjustment, our first purpose is to look at how the relationship between the economic development, the environmental protection and tourism progresses, while reviewing key elements of the relationship between tourism and the environment, with particular reference to the environmental impacts of tourism in Iraq. Following a general overview of the importance of the environment for tourism, a brief review concerning the difficulties of monitoring environmental changes and managing tourism effects in destination areas is presented. Finally, several key questions and research subjects needing further consideration have been identified.
\end{abstract}

Keywords: Environment; Development; Tourism sector; Iraq

\section{Introduction}

Given the presence of natural resources and beautiful scenery (e.g. mountains, oceans, rivers, deserts, marshes), environment is nowadays is one of the most important tourist attractions as it both contains elements of entertainment and constitutes a base for tourism. This allows the practice of several types of tourism in different environments, like skiing and hiking in the mountains, rafting and kayaking on rivers, scuba diving in oceans, desert tours and safaris in deserts [1].

The tourism industry is productive and effective with a significant positive impact on all aspects of environmental economics at both a national and a regional level. It is also a mainstay and an important tool in achieving the goals of comprehensive and sustainable development. It contributes to the promotion of economic growth and it supports the diversification of the base of the national economy, as well as it seeks to increase the level of income. It reduces unemployment, stimulates and attracts investment in tourism facilities and services that maintain an ecological balance in the practice of tourism [2].

Within the context of environmental policy, the importance and special characteristic of the relationship between the environment and the tourism industry is given by the fact that the latter relies strongly on the quality of the former. This allows the creation of a product that suits the demands of tourists who are seeking attractive and unpolluted places to visit [3].

During the last three decades, Iraq has suffered many wars and sustained several environmental problems. The deterioration of the tourism sector in Iraqi was caused by depleted uranium (DU) pollution in many regions, whose effects are harmful for public health. DU is a highly carcinogenic agent which results in poisoning and increased incidence of various cancers types and birth defects.

Approximately 1,200 tones of ammunition were dropped on Iraq grounds during the Gulf Wars in 1991. As a result, contamination occurred in more than 350 sites in Iraq, which subsequently led to a major environmental pollution that, in exchange, constituted a major threat to tourists wanting to visit Iraq.

\section{Methodology}

Iraq is rich in both natural and anthropic elements which are considered the basis of the tourism development. The main question that rises is how natural evolution did and past events in Iraq influence the dimension and structure of tourism? The main hypothesis is that an important role in the drastic diminishing of tourism is greatly related to the degradation of the natural and the anthropic tourism attractions due to the lack of proper resources to protect them, and to reintegrate them in the real tourism industry.

These restrictive elements are, of course, connected to others; especially those are represented by the increase of insecurity, imposed restrictions by the terrorism or by religion. Our analysis was solely directed towards the relationships between some of the environmental issues and the tourism development.

In this respect we used some statistical data provided by the Ministry of Environment and by the Ministry of Tourism, as well as by different central and regional agencies. At the same time, we used different maps to comparatively display the spatial tendencies of the phenomena affecting the tourism.

The maps show some areas that either were contaminated by uranium, after the first war, or were areas strongly affected by desertification. The relationship between the environmental issues and the tourism development constitutes the center of this approach. The complexity and its mutual character of this relation are obviously.

The environmental conditions have an important potential of attraction when not polluted and offer an exotic landscapes, facilitating the tourism development. Concurrently, the tourists may negatively influence the environment through their activities, since the latter are connected to the local infrastructure.

\section{Results and Discussion}

Our analysis individualized some important environmental obstacles for the further development of tourism in Iraq. Such kind of obstacles is represented by uranium pollution, other types of

*Corresponding author: Al-Saadi N, Department of Geography, University of Bucharest, Romania, Tel: +40724249817; E-mail: dr.nawar30@yahoo.com

Received November 27, 2015; Accepted April 01, 2016; Published April 04, 2016

Citation: Al-Saadi N (2016) Environmental Issues Concerning the Economic Development of Tourism in Iraq. J Glob Econ 4: 182. doi:10.4172/2375-4389.1000182

Copyright: ( 2016 Al-Saadi N. This is an open-access article distributed under the terms of the Creative Commons Attribution License, which permits unrestricted use, distribution, and reproduction in any medium, provided the original author and source are credited. 
pollution like desertification, weakness of a functional system for waste collection, etc.

\section{Contamination by depleted uranium in Iraq}

During the first Gulf War in 1991, the use of weapons and ammunition by the United States against Iraq resulted in depleted uranium pollution of the environment and endangerment of the health and lives of thousands of citizens due to the risk of radiation emitted by the weapons and ammunition areas of military operations in the Triangle (Iraqi, Kuwaiti, Saudi Arabia). The environmental disaster could stretch over thousands of years.

In order to approximate the magnitude of the disaster it is enough to estimate to be the overall weight of projectiles dropped on Iraq, which rises to as much as 141-921 tons of explosives, the equivalent of seven atomic bombs, such as those thrown over (Hiroshima) the amount of depleted uranium. Shells ranges between (300-800 tons) following the estimates of the (United Nations committees and the Dutch LAKA foundation) [4].

On the one hand, radioactive materials can cause mass in destruction if unintentionally misused due to the negligence of man, which leads to the occurrence of large-scale disasters, as it is known to have happened in the (Chernobyl), or if intentionally used in chemical weapons in modern warfare, in which case it leaves short- and longterm traces on humans and environment alike [5].

The devastation caused by nuclear wars has lead to large numbers of civilian casualties. These people did not actively join or participate in hostilities and armed conflicts. Radioactive materials also pollute the locations on the ground where they are deposited and their surrounding environment.

Their remains last for many years and affect the genetic code of humans and animals, leading to genetic anomalies and disorders which have an impact on the future generations. Radioactive contamination affects soil, groundwater and aquifers, therefore causing the pollution of elements composing the food chain to humans and animals alike. For the first time in the history of modern warfare, USA and British forces have made large-scale used of weapons containing depleted uranium. UN committees estimated the quantity of depleted uranium shells left by these forces in the theater of operations to be around (300-350 tons). Out of this amount, only (10\%) has been found and recovered, while the rest of it lies buried in the desert sands.

On the other hand, radiation therapy is also known to be used in peaceful means. Thus, it contributes to the well-being of people working in all sectors of the economy (industry, agriculture and services) when used for medical diagnosis and as a possible treatment of many incurable diseases, or when used in scientific research for the purpose of achieving development Table 1 and Figure 1.

\section{Desertification in Iraq}

It is known that for the nature of a system requires that its components interact with each other in a coherent and balanced way and that. On the one hand, causing any kind of damage to any of these factors generates a chain reaction which affects directly or indirectly on other factors and reflects on the general function of the system. On the other hand, natural demolition and constructional processes on it are part of the equation of the natural balance and are harmless for the environment. They are an integral part of the upgrading and developing operations through which the various components of the environment are configured and re-configured.
The existence of a certain natural limit in the demolition process as well as in the soil erosion and desertification in a region are only a part of the process involving the interaction conditions of the environmental factors.

\begin{tabular}{|c|c|c|c|c|c|}
\hline $\mathrm{Nr}$ & Troops Type & $\begin{array}{l}\text { Weight } \\
\text { (Ibs) }\end{array}$ & $\begin{array}{c}\text { Number of } \\
\text { shells }\end{array}$ & $\begin{array}{c}\text { Gear type } \\
\text { (mm) }\end{array}$ & $\begin{array}{l}\text { Weapon } \\
\text { system }\end{array}$ \\
\hline 1 & $\begin{array}{l}\text { Shields United } \\
\text { States }\end{array}$ & $\begin{array}{c}4254 \\
82243\end{array}$ & 50490048 & $\begin{array}{l}105 \\
120\end{array}$ & $\begin{array}{c}\text { Tank or }-1 \\
\text { Tank or A } 11\end{array}$ \\
\hline 2 & U.S. Air Force & 521655 & 783514 & 30 & 15A plane \\
\hline 3 & United States Navy & & & 20 & Phalanx CIA WS \\
\hline 4 & U.S. Marines & $\begin{array}{c}22003 \\
-\end{array}$ & 67436 & $\begin{array}{c}25 \\
105\end{array}$ & $\begin{array}{c}\text { A V-8 B Harrier } \\
\text { Tanks or } 60 / 1 \text { or } \\
\text { tanks }\end{array}$ \\
\hline 5 & United Kingdom & 900 & 88 & 120 & \\
\hline 6 & Total Approximate & $\begin{array}{c}\text { Tanks } \\
87397 \\
\text { Aircraft } \\
543658\end{array}$ & Tanks 9640 & & \\
\hline 7 & The total weight & 631055 & $\begin{array}{l}\text { Aircraft } \\
850950\end{array}$ & & \\
\hline \multicolumn{6}{|c|}{ Source: Al Uqbi, Ali Qassem Khafif (2003) [6]. } \\
\hline
\end{tabular}

Table 1: Approximate amount of depleted uranium shells used against Iraq forces as well as against random military and civilian targets during the Gulf War in 1991.

\begin{tabular}{|c|c|c|}
\hline Land use & $\begin{array}{c}\text { Space A / decare (dunam) } \\
\text { (1 decare = 1 dunam = 1,000 sqm) }\end{array}$ & Percentage(\%) \\
\hline Cities & - & - \\
\hline Farmland & 31349 & 18 \\
\hline Pasture & 25697.2 & 14.5 \\
\hline Forests & 3484.4 & 2 \\
\hline $\begin{array}{c}\text { Water: rivers, lakes } \\
\text { and reservoirs }\end{array}$ & 5761.1 & 3.3 \\
\hline \begin{tabular}{c} 
Marshes and swamps \\
\hline Bare land
\end{tabular} & 3794.4 & 4.2 \\
\hline Total & 97228.2 & 55.9 \\
\hline Sporadic & 173336.8 & 99.6 \\
\hline Grand Total & 2.066 & 0.4 \\
\hline \multicolumn{2}{|c|}{ Source: Al Omar and Abdul Razzaq (2011). [7] } \\
\hline
\end{tabular}

Table 2: Divisions of the current land use systems and divisions of vegetation and their covered areas in Iraq.

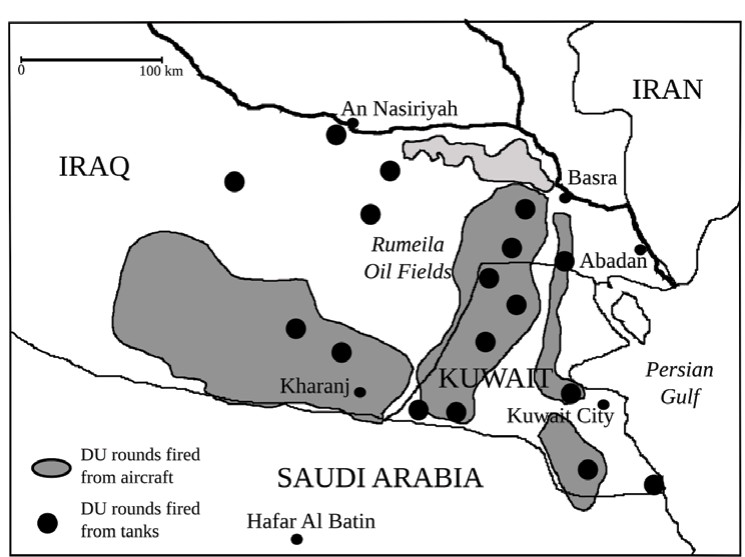

Source:http://www.journal.forces.gc.ca/vo4/no1/research-recherch-eng.asp.

Figure 1: Map displaying the geographical distribution of the Iraqi sites where the depleted uranium rounds were employed during the 1991 Gulf wars. 
The damage occurs therefore within the permissible limits and is be subsequently overcome in environmental processes when natural conditions, such as weather conditions, interact with biological and physical properties of soil in a constructive and balanced form, thus enabling the continuity of the natural cycle.

And biological in this way, the elements of the environment maintain their balance and are safe from erosion and degradation. And then upgrade them for the better, however, the dramatic increase in the numbers of population and then the urgent need for greater amounts of food, pushed many people to spend more and use more resources and larger land and water surfaces at the expense of the tremendous damage of these resources [7].

It is the proprietary rights over various elements of the environment and the owning of the sophisticated technological means that especially damaged the ecological balance equation, whose in favor of the demolition and drift that appeared negative consequences worsen day after day.

The most important of these results is the occurring of desertification as a large-scale phenomenon, which has recently increased, threatening large expanses of land in the world. This occurs mainly because of the negative interference of humans in the exploitation of land, water and other natural resources, exposing large surfaces of land to the dangers of desertification and flooding. As a result, huge amounts of sand dunes cover entire land of surfaces, leading to the loss of rich and fertile soil layers which formed over thousands of years. These areas faced erosion and vegetation loss as well as extinction of species of wild animals. When sand dunes become landmarks of the landscape as a result of desertification, they are an ominous threat for the cities, electrical installations, roads, irrigation canals and agricultural land.

In Iraq features thousands of square kilometers of sand dunes covering areas near cities, as happens nowadays in the Numaniya area, which is only $120 \mathrm{~km}$ from Baghdad, as well as in the Baiji area, on the road between Baghdad and Mosul. These sand dunes also pose a constant threat to the areas to the west of the Euphrates River in central and southern Iraq, in addition to swirling sand storms tossing dust up into the air and causing severe damage to people's health and the facilities [8]. In the civilian areas there is a thick layer of dust covering the leaves of trees, the ground surfaces and the street furniture. The occurrence of this phenomenon is of paramount importance and should raise concern towards greater and more destructive dangers threatening to happen in the future.

The continuing excessive use of the land as well as water and natural resources without taking appropriate measures will lead to a decline in the number of species of wild plants and animals. It is also one of the important elements that hinder the biological properties of soil to maintain and improve its physical properties against erosion and desertification, and at the same time, facilitate the prevalence of hot and dry weather conditions, accompanied by dry winds and lack of rain during summertime [9]. In addition to the presence of desert sands on the edges of the alluvial plain, other factors contributing to the process of desertification are: the failure to take the necessary measures to enact proper legislations to regulate the exploitation of land, water and natural resources; the prevention of harmful practices such as overgrazing, logging and hunting of wild animals; lack of irrigation rationing so as to stop the deadly threat which consisting of millions of tons of quick sands [7].

\section{Sandstorms in Iraq}

Iraq is considered as one of the Middle East's most vulnerable countries to climate changes, as it faces a unique set of environmental degradation factors, such as increased frequency and intensity of extreme weather events, especially the sand and dust storms (SDS). These factors take their toll on socio-economic life and human development in the region [10].

Iraq is affected by the southern and southeasterly wind, which is a dry wind with occasional gusts of $80 \mathrm{Km} / \mathrm{hr}$, occurring from April to early June and again from late September through November. This wind brings along violent dust storms that may rise to heights of several thousand meters. Iraq is also affected by the northern and northwesterly wind, occurring from mid-June to mid-September. This very dry air allows intensive heating and aggravates desertification. It is particularly these two winds that generate severe SDS in the region [11].

A sand or sand storm is a meteorological phenomenon commonly encountered in arid and semi-arid regions. Dust storms arise when a gust front or other strong wind blows loose sand and dirt from a dry surface. Particles are carried by siltation and suspension, a process that moves soil from one place and deposits it to another.

The term "sand storm" is used most often in the context of desert sandstorms, occurring especially in the deserts or other places where sand is a more prevalent soil type than dirt or rock [11].

There, in addition to fine particles obscuring visibility, a considerable amount of larger sand particles is blown closer to the surface. The term "dust storm" is more likely to be used when finer particles are blown across long distances, especially during the dust storms that affect urban areas, as shown in Figure 2.

\section{Factors Causing Desertification in Iraq}

Iraq is exposed to the serious problem of desertification, which was exacerbated start after 1992 till now, affecting the whole country. This was marked increasing of land areas affected by high levels of salinity, significant deterioration of vegetation and larger spaces covered by shifting sand dunes that developed as a result of combined land degradation and wind erosion.

There is a group of interrelated natural and human factors, which contributed to the growing phenomenon of desertification. This is summarized in Figure 3 [7].

Iraqi territory has suffered in the past three decades from severe negligence, which led to the emergence and amplification of the desertification phenomenon in the past few years

Tables 2-4 below display the reality of land degradation in Iraq.

As a synthetic view on desertification processes, the Table 4 shows that over $15 \%$ of the land is characterized by severe and extremely severe desertification. About $60 \%$ are occupied by land with the average desertification processes, and only $23 \%$ belong to light desertification (Table 4).

\section{Natural Conditions that Favoured the Occurrence of Desertification in Iraq}

About $90 \%$ of the surface of Iraq is located within the dry and semi-dry climate with little incidence of severe drought (around $20^{\circ} \mathrm{C}$. High temperatures in summer are beyond of $52^{\circ} \mathrm{C}$, with a high rate of 


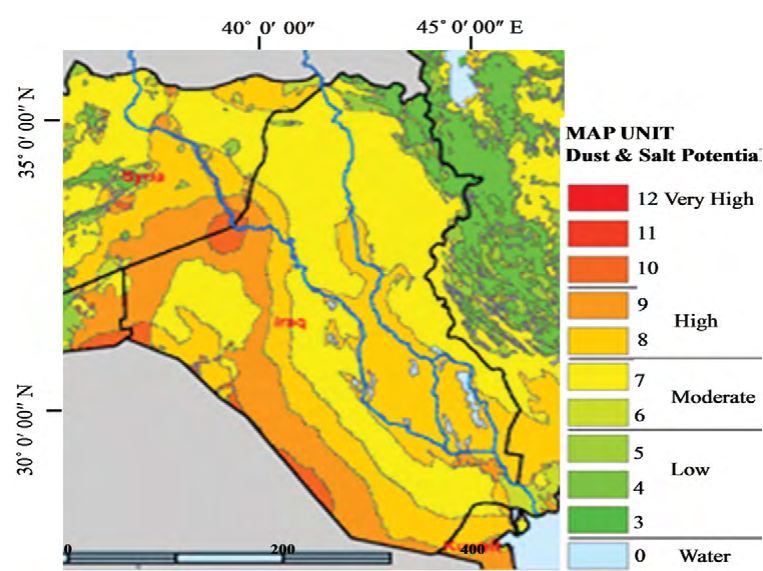

Figure 2: Map of dust transportation and accumulation in Iraq.

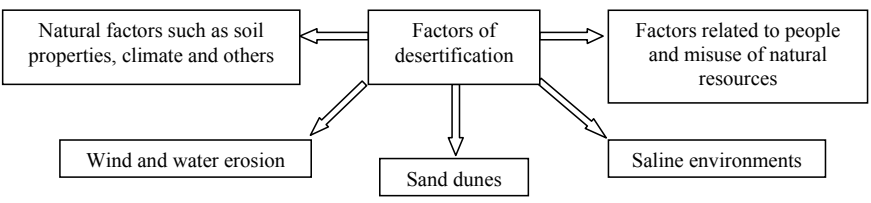

Figure 3: Major factors as a source of the desertification phenomenon in nowa-days Iraq.

evaporation, reaching 2000-3000 $\mathrm{mm}$, especially in the alluvial plain, as well as a high number of sunny days, that sum up to an annual average of 260 days per year.

There is a decline in the amount of precipitation: where less than $150 \mathrm{~mm}$ in most parts of Iraq and not more than average rainfall in the south (40 days) and north (70 days).

There is a lack of humidity, which is otherwise very important for the biological formation of soil, the growth of weeds and recomposition of soil. Little precipitation and humidity are important factors in speeding up the incidence of desertification.

The prevailing wind in Iraq is the north-westerly wind, which is hot and dry in summertime. It locally spreads out dust and has long played an important role in the desertification phenomenon in Iraq.

\section{The topological and natural properties of soil}

Around $60 \%$ of the land in Iraq is made up of a western plateau with local islands which are subject to erosion. Because of the circumstances mentioned above, erosion occurs clearly in these areas, as well as in areas where soils are shallow, dry and poor (e.g. limestone soils, rock soils). A couple of valleys that are exposed and are soon to be submerged in sand. The alluvial plain in Iraq constitutes $20 \%$ of the region and is also exposed and lends itself to two desertification phenomena [8].

First phenomenon: It is generated by the exposure to coarse sandy sediments advancing from the sandy areas adjacent to the region.

Second phenomenon: It is generated by high levels of groundwater and increased salinization due to poor drainage and low elevation of the ground, causing swamps and marshes to form, as well as soil degradation and the loss of its production properties. In the northern regions are shown in which the phenomenon of water erosion is less intense because of the decline in precipitation rates.

\section{The Relationship between the Tourism Development and the Environment}

Tourism is almost wholly dependent on the environment. Natural resources (beaches, seas, mountains, lakes, rivers etc) and manmade resources (historic cities, heritage buildings and sites, monuments etc) constitute the primary source of tourism. Any degradation of the primary sources is likely to lead to a decline of tourism. Therefore, their analysis within economics is particularly relevant to tourism.

Tourism is the largest commercial activity nowadays. It has become a major industry on a global scale and is expected to grow uninterrupted. The number of tourists at an international level has tripled during the past two decades, and revenues in international tourism rose to 1.3 trillion USD in 2012 [12].

The share of international tourism in the gross domestic product of many countries ranges between $15 \%$ and $30 \%$, and international tourism is considered an important way to contribute to the economic growth of developing countries.

Tourism it has a marked impact on the demand for exhaustible and renewable resources. It generates significant wastes and thus disposal problems [13].

The operation of tourism firms reflects the market driven characteristics of other economic sectors. Extended tourism expansion or concentration in certain destinations has neglected the long term dependence of the industry on environment and led over exploitation of natural resource base and the generation of non-priced effects [14].

The environmental effects, widely defined, include cultural and social elements, and are probably the biggest problem of tourism. Areas where overcrowding and overdevelopment occur are often relatively small and possess fragile environments. At peak season visitors can

\begin{tabular}{|c|c|c|c|}
\hline No & Quality of soil class & $\begin{array}{c}\text { Surface } \\
\text { Area } \\
\left(\mathbf{1 0 0 0} \mathbf{~ k m}^{\mathbf{2}}\right)\end{array}$ & $\begin{array}{c}\text { Percentage } \\
\mathbf{( \% )} \text { of the } \\
\text { total area }\end{array}$ \\
\hline 1 & Excellent quality for irrigated crops & 16.8 & 3.7 \\
\hline 2 & Good quality for irrigated crops & 24.5 & 5.4 \\
\hline 3 & Medium quality for irrigated crops & 16.7 & 3.7 \\
\hline 4 & Excellent quality for rained and irrigated crops & 2.5 & 0.6 \\
\hline 5 & Good to excellent quality for rained and & 12.8 & 2.8 \\
\hline 6 & irrigated crops & 10.7 & 2.4 \\
\hline 7 & Good quality for irrigated crops and medium & & 6.9 \\
\hline 8 & quality for rained crops & 30.7 & 74.5 \\
\hline 9 & Good quality for grazing and forest & 329.7 & 100.00 \\
\hline
\end{tabular}

Source: Al Omar and Abdul Razzaq 2011 [7].

Table 3: Soil classification in terms of suitability for agricultural purposes in Iraq.

\begin{tabular}{|c|c|c|c|}
\hline No & Degree of desertification & $\begin{array}{c}\text { Space estimates } \\
\text { (Thousand acres) }\end{array}$ & $\begin{array}{c}\text { Percentage } \\
\text { (\%) }\end{array}$ \\
\hline 1 & Light desertification & 45.138 & 23.1 \\
\hline 2 & Average desertification & 99.950 & 57.6 \\
\hline 3 & Severe desertification & 21.908 & 12.6 \\
\hline 4 & Extremely severe desertification & 4.823 & 2.8 \\
\hline & \multicolumn{2}{|r|}{ Source: Filial 2012 [12]. } \\
\hline
\end{tabular}

Table 4: Degree of desertification in Iraq and, space covered and the estimated percentage of total surface. 
outnumber the resident population. Hosts, tourism firms are seldom aware of the unintentional damage being caused to monuments, paintings, ecosystem [15]. Other effects are more deliberate, e.g. offroad use of vehicles. Excess numbers Also increases the demand for secondary resources, water, energy which might be scarce at certain destinations [16].

Loss of flora and fauna occurs due to tourism expansion. The influx of tourists with a different life-style, large financial resources, and nonindigenous services can not only disturb existing economic life but also can destroy the cultures [17].

Tourism turns out to be beneficial for the environment, since high-quality tourism products also demand protective measures for themselves, which are implicitly intended to protect the physical features of the environment, the historical sites, the monuments and the wildlife. Usually the recreation and tourism are among the first reasons in the establishment and development of different types of protected areas, which eventually become scenic areas with major attractions and the basis for what is known as ecotourism.

The historical and cultural heritage determines to a great extent the attractiveness of a country for tourists, encouraging governments to protect and preserve them. Therefore, many countries are making great efforts to provide regular protection for cities, villages and areas of archaeological heritage and aesthetic value, especially those of historical and artistic significance. Tourism also plays a significant role in the protection of mountain areas. Conversely, tourism has unfortunately created excessive pollution in some areas and many countries are now dealing with increased levels of atmospheric pollution corresponding to the peak seasonality of tourism.

The relationship between tourism and the environment reflects the delicate balance between the tourism development and the environmental protection, while it also confirms the urge that tourism should not be achieved in a way that would inflict damage to the environment $[18,19]$. Interests of social and economic development should not prevail over the safeguarding of the local population of the receiving tourism areas, the environment, the natural resources and historical and cultural sites, all of which are major factors of attraction for tourism.

The Manila Declaration emphasizes that these resources are part of the universal heritage of mankind and that the national communities as well as the international community should takes the necessary steps to ensure their preservation. Long-term environmental planning is a prerequisite for the establishment of an equitable balance between tourism and the environment. It is also a prerequisite and a priority for tourism to become developmentally viable.

\section{Conclusion}

In conclusion to the above discussion, we can simply reiterate that environmental issues have become pivotal in economics of tourism. The more intensive is the insistence on the subjects such as sustainable development, rational use of resources, and mitigation of negative results of expansion of tourism, widespread is the desire for sound management of tourist resources. Sustained active role of firms and governments is considered vital for the future of tourism development in Iraq.

In order to preserve the environment, the concept of "sustainable development" for economic growth has emerged and has been accepted particularly in developing countries which cover large areas, have high population densities and dispose of vast and mostly untapped natural resources.

The sustainable development aims to rationalize consumption without exhausting the natural resources in order to ensure the wellbeing of future generations.

The risks of the global environment nowadays are mainly risks that endanger the oceans and seas, which belong to the whole world. Therefore, the problem of their protection has become the responsibility of the global community.

Any degradation in the environment leads to a disruption of the natural balance, leaving the negative effects on prolonged periods of time. The longer these disruptions will continue the more difficult will it become to redressing the balance and restore the ecosystems to their original state.

We conclude that national accounts have neglected the traditional environment, since the depletion of natural capital is often overlooked and finance is seldom directed towards protecting and restoring this capital.

\section{References}

1. Alejandro, Pablo SJ (2008) Tourism development: Economics, management and strategy. Nova Science Publishers, New York.

2. Andrew H (2008) Environment and tourism. Taylor and Francis, USA.

3. WCED (1987) World Commission on Environment and Development. Oxford University Press, New York.

4. Al-Jubouri, Jabar R (1994) The size of forces and weapons that were used during the war on Iraq, the International Scientific Symposium on the environment post-war Iraq. The Iraqi Association to improve the environment Baghdad pp: 19

5. Mahmoud, Abdul K (2000) The environmental impact and the health of radioactive material, with particular reference to depleted uranium, paragraphs scientific conference on the impact of the use of depleted uranium weapons in humans and the environment first part. The Ministry of Higher Education and Scientific Research p: 15.

6. Al Uqubi, Ali QK (2003) The economic costs of pollution depleted uranium used against Iraq in 1991. (6)

7. Basilm HS (2001) Sustainable development environment and economic frame work integration. The Treasury pp: 23-36.

8. Al Omar, Razzaq MA (2011) The environmental situation in Iraq, Second part Natural ecosystems. The Ministry of Environment, Iraq pp: 58-62.

9. Filani M (1975) The role of national tourist associations in the preserving of the environment of Africa. Journal of Travel Research pp: 2.

10. UN (2013) Sand and dust storm fact sheet. Scientific research 5: 1084-1094

11. Tourism Authority of Iraq (2010) A symposium on the terrain in Iraq

12. Al-Tai, Filial (2012) Ministry of Water Resources. Search the reality of desertification in the Republic of Iraq and ways to combat it.

13. UNWTO (2012) International tourism receipts surpass US\$ 1 trillion in 2011.

14. Stabler M, Goodall B (1996) Environmental auditing in planning for sustainable island tourism, England.

15. Stabler M, Goodall B (1997) Environment awareness, action and performance in the tourism industry, Tourism Management 18: 19-33.

16. Goodall B (1992) Environmental auditing for tourism. Recreation and Hospitality Management 4: 60-74.

17. Romeril M (1998) Tourism and the environment: accord or discord. Tourism Management pp: 76-77.

18. Perman R (1999) Natural Resource and Environmental Economics. Longman, USA.

19. World Tourism Organization-WTO (1980) The Manila Declaration on World Tourism. 